\title{
OUTCOME OF EXTERNAL AND INTERNAL DRAINAGE OF URINE AFTER ANDERSON HYNES PYELOPLASTY - A COMPARATIVE STUDY
}

\author{
AM SHAHINOOR ${ }^{1}$, MMR SHIBLI $^{2}$, MAB AKAN $^{3}$, M ANISUZZAMAN $^{4}$, MN ISLAM $^{5}$, MN ZAMAN $^{6}$, \\ MTH SIDDIQUI
}

\begin{abstract}
Background: Hydronephrosis in children is a common abnormality of the kidney. Surgical intervention in patient with hydronephrosis is to improve urinary drainage and to preserve renal function. Surgery (Anderson Hynes pyeloplasty: A-H pyeloplasty ) can be done with or without (Nephrostomy tube) D-J stent.Here we are describing our comparative experience between A-H pyeloplasty with D-J stent and A-H pyeloplasty with nephrostomy tube, at Bangabandhu Sheikh Mujib Medical University(BSMMU) to show the postoperative advantages of the former over the latter.
\end{abstract}

Objectives: To assess functional outcome after A-H pyeloplasty with or without D-J stent in patients of unilateral hydronephrosis. Post operatively renal function was estimated after 3 months by DTPA renogram.

Methods: It was a prospective study at Paediatric Surgery department of Bangabandhu Sheikh Mujib Medical University from April 2009 to October 2010. Twenty eight ( age, sex, side and type of operation matched) patients of unilateral hydronephrosis were

1. Dr. A.M. Shahinoor, Medical Officer, Department of Paediatric Surgery, Bangabandhu Sheikh Mujib Medical University

2. Dr. Muhammad Mizanur Rahman Shibli, Assistant Registrar, Department of Surgery, Dhaka Dental College Hospital, Dhaka

3. Dr. Md Abu Bakar Akan, Medical Officer, Upozila Health Complex, Swarupkati, Pirojpur.

4. Dr. Md. Anisuzzaman, Registrar, Department of Surgery, Holy Family Red Crescent Hospital, Dhaka

5. Dr. Md. Nazrul Islam, Medical Officer, Department of Paediatric Surgery, Bangabandhu Sheikh Mujib Medical University

6. Dr. Md. Nooruzzaman, OSD, DG Health

7. Md. Tosaddeque Hossain Siddiqui, Associate Professor, Department of Paediatric Surgery, Bangabandhu Sheikh Mujib Medical University

Correspondence to: Dr. A.M. Shahinoor, Medical Officer, Department of Paediatric Surgery, Bangabandhu Sheikh Mujib Medical University. E-mail: dr_phlip78@yahoo.com included in the study and divided into two Groups: Group $A\left(n_{a}=15\right)$ and Group $B\left(n_{b}=13\right)$ patients who underwent A-H pyeloplasty with D-J stent and A-H pyeloplasty with nephrostomy tube respectively.

Child with bilateral hydronephrosis, hydronephrosis with associated anomalies like horseshoe kidney, ectopic kidney, solitary kidney, hydronephrosis with vesico ureteric reflux and redopyeloplasty were excluded in this study.

Unpaired "t" test and Chi-square test were used for statistical analysis whereas postoperative hospital stay and renal functional improvement were used as parameters of the study.

Results: For study Group A (A-H pyeloplasty with D-J stent) postoperative hospital stay were significantly lesser $(P<0.00)$ than the GroupB ( $A-H$ pyeloplasty with nephrostomy tube).

Post operative split renal function and glomerular filtration rate (GFR) in Group $A$ was improved (percentage) than Group B.

Conclusion: This study reveals postoperative shorter hospital stay and improved postoperative split renal function in A-H pyeloplasty with D-J stent.

Key words: Postoperative, A-H pyeloplasty, Unilateral Hydronephrosis, D-J stent

\section{Introduction}

Hydronephrosis in children is a common abnormality of the kidney which can be defined as an aseptic dilatation of the renal collecting system as a result of either inadequate drainage through the pelviureteric junction or retrograde flow of urine. Congenital pelviureteric junction obstruction (PUJO) may be 
primary i.e. idiopathic or secondary due to crossing abbarent vessels, adhesive band, fibro epithelial polyp etc. Idiopathic hydronephrosis is the most common $(44 \%)$ cause of PUJO'1 .

Ultrasonography is the simple non-invasive investigation to diagnose hydronephrosis both antenatally and post-natally. Intravenous urography is an invasive tool for evaluation of hydronephrosis. But radio-nuclide study is the most useful, informative and sophisticated investigation in the functional evaluation of effect of hydronephrosis. It can give detail information regarding differential renal function, GFR and drainage function of each kidney and it is also helpful in follow up study. It is a small molecule that is exclusively filtered by the glomeruli is neither secreted nor reabsorbed by renal tubules and $95 \%$ of tracer excreted through urine within 24 hours and no retention of compound had been demonstrated in the kidney. DTPA is cheap, easily available and has no documented side effects ${ }^{2}$.

There are several types of operation for surgical treatment of hydronephrosis like Anderson-Hynes (A$\mathrm{H})$ pyeloplasty, Trendelenburg procedure, ureterocalicostomy, Heineke-Meckuliez procedure, Flap procedure etc. The Anderson-Hynes dismembered pyeloplasty is the gold standard treatment for the hydronephrosis ${ }^{2}$.

The goal of surgical intervention in patient with hydronephrosis is to improve urinary drainage and to preserve renal function. Surgery (A-H pyeloplasty) can be done with or without (Nephrostomy tube) D-J stent.

To show the postoperative advantages of $\mathrm{A}-\mathrm{H}$ pyeloplasty with $\mathrm{D}-\mathrm{J}$ stent over A-H pyeloplasty with nephrostomy tube, we are describing our comparative experience of these two procedures in terms of postoperative hospital stay. improvement of split renal function and GFR

Postoperative advantages of Anderson-Hynes Pyeloplasty with D-J stent over without D-J stent in the surgical treatment of unilateral hydronephrosis

\section{Materials and Methods}

It was a prospective study conducted at the department of Paediatric Surgery of Bangabandhu Sheikh Mujib Medical University, Dhaka, Bangladesh during April 2009 to October 2010.

Total 28 confirmed unilateral hydronephrosis patients were selected in such a way that their age, sex, side and type of operation matched well for this comparative study.

They were divided into two groups: $G r . A\left(n_{a}=15\right)$ underwent $A-H$ pyeloplasty with $D-J$ stent and designated as 'Study Group'; $\mathrm{Gr}$. B $\left(\mathrm{n}_{\mathrm{b}}=13\right)$ underwent A-H pyeloplasty with nephrostomy tube and designated as 'Control Group.

As parameter, postoperative hospital stay, DTPA renogram with split function was done 3 months after operation and also GFR in same duration.

Unpaired ' $t$ ' test and Chi-square test were used for statistical analysis of the observed results.

Patients with bilateral hydronephrosis, hydronephrosis with associated anomalies like horseshoe kidney, ectopic kidney, solitary kidney and hydronephrosis with vesico ureteric reflux were excluded in this study.

\section{Results}

The base line parameters including age, sex,side and type of operation were same in group $A$ and group $\mathrm{B}($ Table-I).

Postoperative hospital stay for unilateral hydronephrosis patients in Group-A and Group-B were $4.93+1.28$ days and $13.46+2.30$ days respectively. There was significant difference $(P<0.001)$ between two groups with lesser hospital stay for A-H pyeloplasty with D-J stent (Table-II).

Table III shows, In Group-A, preoperative split renal function was Mean (+SD) $34.20+16.40$ and range was 7.00 - 75.00 .

3 months postoperative split renal function was mean + SD37.53 + 13.12 and range was $19.00-64.00$. So the improvement of split renal function of $30.45 \%$. In Group B Preoperative split renal function was mean + SD $31.23+18.29$ and range was $15.00-83.00 .3$ months postoperative split renal function was mean + SD $30.46+11.69$ and range was $9.00-46.00$.Sothe improvement of split renal function was $13.44 \%$.

In Group A, preoperative GFR was mean SD $23.47 \pm 0.54$ and range was 11.50-51.10 and postoperative GFR was mean SD30.39 \pm 14.41 and range was 15.1068 .90 .So the improvement of GFR was $32.75 \%$. In Group B, preoperative GFR was mean SD23.60 \pm 8.69 and range was 13.5043 .70 and post operative GFR was mean SD $26.66 \pm 12.50$ and range was 5.60 49.50.So the improvement of GFR was $15.06 \%$. (table-IV)

Postoperative split renal function and GFR were improved (percentage) in Group-A. 
Table-I

Baseline parameters in all patients (with stent and without stent)

\begin{tabular}{llll}
\hline Baseline parameters & $\begin{array}{l}\text { Group A } \\
(\mathrm{na}=15)\end{array}$ & $\begin{array}{l}\text { Group B } \\
(\mathrm{nb}=13)\end{array}$ & P value \\
\hline Age (month) & 1.50180 .00 & 3.50156 .00 & $0.559^{\text {ns }}$ \\
& $(53.77 \pm 60.03)$ & $(3.50156 .00)$ & \\
Sex (percentage) & Male: $9(60 \%)$ & Male: $8(61.5 \%)$ & $>0.05^{\text {ns }}$ \\
& Female:6(40\%) & Female: $5(38.4 \%)$ & \\
Side of involvement & Right: $6(40 \%)$ & Right: $5(38.5 \%)$ & $0.934^{\text {ns }}$ \\
& Left: $9(60 \%)$ & Left: $8(61.5 \%)$ & \\
\hline
\end{tabular}

aUnpaired Student's 't' test

${ }^{b}$ Chi square test

ns $=$ Not significant

Table-II

Postoperative hospital stay for A-H pyeloplasty with $D$-J stent and without $D$-J stent

\begin{tabular}{lccc}
\hline $\begin{array}{l}\text { Hospital } \\
\text { stay (days) }\end{array}$ & $\begin{array}{c}\text { Group } A \\
(\mathrm{n}=15)\end{array}$ & $\begin{array}{c}\text { Group B } \\
(\mathrm{n}=13)\end{array}$ & P value \\
\hline Mean $\pm S D$ & $4.93 \pm 1.28$ & $13.46 \pm 2.30$ & $0.0001^{* \star *}$ \\
Range & 4.009 .00 & 12.0017 .00 & \\
\hline
\end{tabular}

Unpaired Student's 't' test

$* * *=$ Significant $(P<0.001)$

Table-III

Status of split renal function among patients of A-H pyeloplasty with D-J stent and without D-J stent.

\begin{tabular}{|c|c|c|c|c|c|c|c|c|}
\hline \multirow{2}{*}{$\begin{array}{l}\text { Split renal } \\
\text { function in } \\
\text { patients }\end{array}$} & \multicolumn{2}{|c|}{ Preoperative } & \multicolumn{2}{|c|}{$\begin{array}{c}\text { At } 3 \text { month } \\
\text { postoperative }\end{array}$} & \multicolumn{2}{|c|}{$\begin{array}{c}\text { Change at } \\
3 \text { month }\end{array}$} & \multicolumn{2}{|c|}{$\begin{array}{l}\text { Percent change } \\
\text { at } 3 \text { month }\end{array}$} \\
\hline & Mean $\pm S D$ & Range & Mean \pm SD & Range & Mean $\pm S D$ & Range & Mean $\pm S D$ & $\overline{\text { Range }}$ \\
\hline & $34.20 \pm 16.40$ & 7.0075 .00 & $37.53 \pm 13.12$ & 19.0064 .00 & +3.33 & 11.00 to +17.00 & +30.45 & $\begin{array}{l}+4.00 \\
\text { to }+9.00\end{array}$ \\
\hline Group B & $31.23 \pm 18.29$ & 15.0083 .00 & $30.46 \pm 11.69$ & 9.0046 .00 & 0.77 & 38.00 to +25.00 & +13.44 & $\begin{array}{c}+12.00 \\
\text { to }+17.00\end{array}$ \\
\hline
\end{tabular}

Table-IV

Status of glomerular filtration rate among patients of $A-H$ pyeloplasty with $D-J$ stent and without $D$-J stent.

\begin{tabular}{|c|c|c|c|c|c|c|c|c|}
\hline \multirow{2}{*}{$\begin{array}{l}\text { Split renal } \\
\text { function in } \\
\text { patients }\end{array}$} & \multicolumn{2}{|c|}{ Preoperative } & \multicolumn{2}{|c|}{$\begin{array}{c}\text { At } 3 \text { month } \\
\text { postoperative }\end{array}$} & \multicolumn{2}{|c|}{$\begin{array}{l}\text { Change at } \\
3 \text { month }\end{array}$} & \multicolumn{2}{|c|}{$\begin{array}{l}\text { Percent change } \\
\text { at } 3 \text { month }\end{array}$} \\
\hline & Mean \pm SD & Range & Mean $\pm S D$ & Range & Mean $\pm S D$ & Range & Mean $\pm S D$ & Range \\
\hline Group A & $23.47 \pm 0.54$ & 11.5051 .10 & $30.39 \pm 14.41$ & 15.1068 .90 & +6.93 & 2.10 to +23.30 & +32.75 & $\begin{array}{r}12.21 \text { to } \\
+137.39\end{array}$ \\
\hline Group B & $23.60 \pm 8.69$ & 13.5043 .70 & $26.66 \pm 12.50$ & 5.6049 .50 & +3.07 & 14.80 to +12.70 & +15.06 & $\begin{array}{l}72.55 \text { to } \\
+87.41\end{array}$ \\
\hline
\end{tabular}




\section{Discussion}

Hydronephrosis in children is a common abnormalities in the upper urinary tract, occurring approximately 1 in 1250 live birth and male-female ratio $2: 1 .{ }^{1}$ The aim of treatment of hydronephrosis is the excision of adynamic segment or to make it capacious. There are several types of operation for hydronephrosis but Anderson-Hynes dismembered pyeloplasty is the gold standard ${ }^{2}$.

In this study the length of postoperative hospital stay in Group AA-H pyeloplasty with D-J stent were Mean + SD 4.93 + 1.28 and range 4.00-9.00 and in Group B A-H pyeloplasty without D-J stent (Nephrostomy tube) Mean + SD $13.46+2.30$ and range $12.00-17.00$.

Postoperative hospital stay between Group A and Group B patients of our series showed highly significant difference $(P<0.001)$ with very shorter hospital stay in A-H peyloplasty with D-J stent Stented patients had their double $\mathrm{J}$ stent removed using cystoscopy under general anaesthesia as a day case

In a study of "Improving splintage technique in pyeloplasty" it was found that the use of D-J stent was associated with a much shorter postoperative hospital stay compared with the external drainage ${ }^{3}$.

Regarding postoperative hospital stay between 2.8 and 5.3 days it was shorter in stented patients than unstented patients ${ }^{4}$. In another study it was found that the use of ureteric stent was significantly favourable with respect to shorter postoperative hospital stay $^{5}$.

In this study, A-H pyeloplasty with D-J stent was very shorter postoperative hospital stay than A-H pyeloplasty without D-J stent (Nephrostomy tube) are consistent or match with above mention study.

Differential renal function and GFR was the main indicator for the analysis of outcome of A-H pyeloplasty postoperatively.

The outcome of pyeloplasty in a study, it showed that improvement achieved in $87 \%$ of patients and there was continued obstruction in $13 \%$ of patients ${ }^{3}$.

Regarding postoperative differential renal function, it was found that improvement observed in patients who were inserted with D-J stent was routinely ${ }^{4}$.

Following pyeloplasty compared to their respective preoperative baseline a significant improvement occurred earlier in the stented patient (at 3.1 months) ${ }^{5}$.
It is noted that more than $5 \%$ increase of renal function postoperatively is considered as improvement, change within $5 \%$ is considered as preservation or static and decrease the function more than $5 \%$ is considered as deterioration of differential renal function ${ }^{6}$.

In this study, Improvement in postoperative differential renal function was $30.45 \%$ in group $A$ and $13.44 \%$ in group B. It showed an obvious percentage in improvement.

GFR of both the groups (A-H pyeloplasty with D-J stent and $\mathrm{A}-\mathrm{H}$ pyeloplasty with nephrostomy tube) were improved, though improvement is seen more in D-J stent group (32.75\%) than nephrostomy tube group (15.06\%).

\section{Conclusion}

Outcome depends on postoperative hospital stay and postoperative split renal function. This study reveals postoperative shorter hospital stay and improved postoperative split renal function in $\mathrm{A}-\mathrm{H}$ pyeloplasty with D-J stent.

\section{References}

1. Joyner B.D, Mitchell M.E. Ureteropelvic junction obstruction. In Grosfeld J.L. (Ed.), Pediatric Surgery, $6^{\text {th }}$ ed, Mosby Elsevier, Philadelphia, 2006; p. 1723-40.

2. Sarin YK., Gupta and Nagdere N. Pediatric pyeloplasty, intubated vs non intubated.Ann Intern Med 2006 July.

3. Sibley G NA, Graham M D, Smith M L, Doyle T. Improved splintage techniques in pyeloplasty. Ann Intern Med 1987; p.489-91.

4. Choo K L, Borzi P A. Surgical correction of pelviureteric junction obstruction in childhooddorsal lumbotomy approach and selective internal ureteric stenting.Ann Intern Med 2001; p.152-56.

5. Elmalik K, Chowdhury M M, and Capps S N J.. Ureteric stent in pyeloplasty: A help or a hindrance? Ann Intern Med 2008 ; p.275-79.

6. Park S, Ji Y H, Park K H, Han D H, Kim K S. Difference in results of ultrasonography and Diuretic renogram after pyeloplasty in Children with unilateral ureteropelvic junction obstruction. Ann Intern Med 2009; p. 595-601. 